\title{
Utilization of $\left[{ }^{15} \mathrm{~N}\right]$ glutamate by cultured astrocytes
}

\author{
Marc YUDKOFF,* Itzhak NISSIM, Klaus HUMMELER, Marvin MEDOW and David PLEASURE \\ Division of Biochemical Development and Molecular Disease, Children's Hospital of Philadelphia, and Department of \\ Pediatrics, University of Pennsylvania School of Medicine, 34th Street and Civic Center Boulevard, Philadelphia,
} PA 19104, U.S.A.

\begin{abstract}
The metabolism of $0.25 \mathrm{~mm}-\left[{ }^{15} \mathrm{~N}\right]$ glutamic acid in cultured astrocytes was studied with gas chromatographymass spectrometry. Almost all ${ }^{15} \mathrm{~N}$ was found as $\left[2-{ }^{15} \mathrm{~N}\right]$ glutamine, $\left[5-{ }^{15} \mathrm{~N}\right]$ glutamine and $\left[{ }^{15} \mathrm{~N}\right]$ alanine after $210 \mathrm{~min}$ of incubation. Some incorporation of ${ }^{15} \mathrm{~N}$ into aspartate and the 6-amino position of the adenine nucleotides also was observed, the latter reflecting activity of the purine nucleotide cycle. After the addition of $\left[{ }^{15} \mathrm{~N}\right]$ glutamate the ammonia concentration in the medium declined, but the intracellular ATP concentration was unchanged despite concomitant ATP consumption in the glutamine synthetase reaction. Some potential sources of glutamate nitrogen were identified by incubating the astrocytes for $24 \mathrm{~h}$ with $\left[5-{ }^{15} \mathrm{~N}\right] \mathrm{glutamine}$, $\left[2-{ }^{15} \mathrm{~N}\right]$ glutamine or $\left[{ }^{15} \mathrm{~N}\right] \mathrm{alanine}$. Significant labelling of glutamate was noted with addition of glutamine labelled on either the amino or the amide moiety, reflecting both glutaminase activity and reductive amination of 2-oxoglutarate in the glutamate dehydrogenase reaction. Alanine nitrogen also is an important source of glutamate nitrogen in this system.
\end{abstract}

\section{INTRODUCTION}

Maintenance of a relatively low extracellular glutamate concentration is essential to effective communication between glutamatergic neurons, and efficient systems for glutamate uptake have developed in both nerve terminals and glia (Logan \& Snyder, 1972; Henn et al., 1974; Ramaharobandro et al., 1982; Drejer et al., 1982; Gordon \& Balázs, 1983). Indeed, astrocyte glutamate transport may be considered the beginning of a cycle leading to formation of glutamine and the subsequent export of this amino acid to neurons, where it is cleaved to neurotransmitter glutamate (Van den Berg et al., 1976; Shank \& Aprison, 1981). This cycle is maintained in part by the enrichment of astroglia with glutamine synthetase (Norenberg, 1979; Norenberg \& Martinez-Hernandez, 1979) and of nerve endings in glutaminase (Baldessarini \& Yorke, 1974; Bradford \& Ward, 1976). Concordant with this schema, available data indicate that much glutamate carbon accumulated by astrocytes is converted into glutamine or is oxidized to $\mathrm{CO}_{2}$ (Yu et al., 1982, 1984). The disposition of glutamate nitrogen, however, remains largely undefined because of the unavailability of radioactive nitrogen isotopes suitable for studies in vitro. Berl et al. (1962) studied ${ }^{15} \mathrm{NH}_{4} \mathrm{Cl}$ metabolism in whole brain, but the isotope-ratio-mass-spectrometry techniques that they utilized for ${ }^{15} \mathrm{~N}$ quantification require a much larger sample size than usually is available from preparations in vitro. More recently, the radioactive ${ }^{13} \mathrm{~N}$ species has been used to study cerebral ${ }^{13} \mathrm{NH}_{3}$ metabolism (Cooper et al., 1979; Lockwood et al., 1979; Freed \& Gelbard, 1980), but the extremely short half-life of this isotope $(10 \mathrm{~min})$ severely curtails the duration of experiments.

We have previously used gas chromatography-mass spectrometry (g.c.-m.s.), which allows quantification of
${ }^{15} \mathrm{~N}$ in extremely small samples, to study ${ }^{15} \mathrm{NH}_{3}$ metabolism in organotypic cerebellar explants and cultured astroyctes (Yudkoff et al., 1983a,b, 1984). In the present study we utilized $\left[{ }^{15} \mathrm{~N}\right]$ glutamate to define the major metabolic fate of glutamate nitrogen in cultured astrocytes. Our results indicate that synthesis of $\left[2-{ }^{15} \mathrm{~N}\right]$ glutamine is only one of several important routes of astrocyte glutamate metabolism. Transamination reactions appear to be important, as manifested by the appearance of glutamate nitrogen in alanine and the 6-amino position of the adenine nucleotides. The latter observation indicates an active role for the purine nucleotide cycle in astrocyte nitrogen metabolism.

\section{MATERIALS AND METHODS}

\section{Materials}

All ${ }^{15} \mathrm{~N}$-labelled compounds were purchased from MSD Ltd. (Montreal, Canada). Freeze-dried NADH and glutamate dehydrogenase were purchased from Sigma Chemical Co. (St. Louis, MO, U.S.A.). All ion-exchange resins were from Bio-Rad Laboratories (Richmond, CA, U.S.A.). SAX and C-18 preparative columns were from J. T. Baker Chemical Co. (Phillipsburg, NJ, U.S.A.). Reagents used for formation of derivatives were from Regis Chemical Co. (Chicago IL, U.S.A.). o-Phthalaldehyde and $S$-methylcysteine were purchased from Pierce Chemical Co. (Rockford, IL, U.S.A.). All other reagents were of the highest available grade and were purchased from Fisher Chemical Co. (Silver Springs, MD, U.S.A.).

\section{Preparation of astrocytes}

Astroglia were prepared from neonatal-rat whole forebrains by selection in a serum-free defined medium according to a method that we have described elsewhere

* To whom correspondence should be addressed. 
(Kim et al., 1983). All experiments were performed 4 days after addition of $5 \mu \mathrm{g}$ of partially purified bovine pituitary glial growth factor $/ \mathrm{ml}$. At the time of the experiments, the astrocytes were in an almost confluent monolayer at a density of approx. $2 \times 10^{6}$ cells/dish in sterile Falcon plastic $35 \mathrm{~mm}$ culture dishes. The culture medium $(2 \mathrm{ml})$ was modified Ham's F-12 medium (Kim et al., 1983). No serum was added. The purity of the preparation was determined by indirect immunofluorescence with anti-(glial fibrillary acidic protein) serum. For all experiments purity exceeded $98 \%$.

\section{Incubation conditions}

All experiments were done in astrocytes cultured for 9 days. In an initial investigation, the utilization of glutamate and other amino acids was studied by replacing the culture medium with $2 \mathrm{ml}$ of fresh medium. The cultures were kept at $37^{\circ} \mathrm{C}$ under air $/ \mathrm{CO}_{2}(19: 1)$ for the duration of the experiment. At the indicated times, $20 \mu \mathrm{l}$ of medium was removed for amino acid determination. The disappearance of individual amino acids from this medium is expressed as a percentage of the starting concentration. Amino acid concentrations were measured also in the original 'steady-state' medium, i.e. before replacement with fresh medium, and in the astrocytes. This was done by removing the steady-state medium, quickly washing the cells with $2 \mathrm{ml}$ of cold $140 \mathrm{~mm}$ -

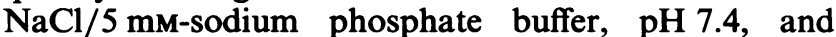
adding $2 \mathrm{ml}$ of $10 \mathrm{~mm}-\mathrm{HCl}$ kept at $4{ }^{\circ} \mathrm{C}$. The astrocytes then were frozen and thawed three times in order to liberate intracellular contents.

In order to ascertain the metabolic fate of glutamate $\mathrm{N}, 52 \mu \mathrm{l}$ of $10 \mathrm{mM}-\mathrm{L}-\left[{ }^{15} \mathrm{~N}\right]$ glutamate (99 atom\% excess) was added to the astrocytes in $2 \mathrm{ml}$ of 'steady-state' medium. The final L-[ $\left.{ }^{15} \mathrm{~N}\right]$ glutamate concentration was $0.25 \mathrm{~mm}$. The culture dishes immediately were placed in an incubator at $37^{\circ} \mathrm{C}$ in an air $/ \mathrm{CO}_{2}(19: 1)$ environment. At the indicated times $200 \mu \mathrm{l}$ of $4 \mathrm{M}-\mathrm{HClO}_{4}$ was added and the bottom of the dish was scraped with a rubber spatula to liberate intracellular contents. After centrifugation for $1 \mathrm{~min}$ at $9000 \mathrm{~g}$ in an Eppendorf Microfuge, the supernatant was neutralized with $\mathrm{KHCO}_{3}$. The resulting supernatants were kept at $-80^{\circ} \mathrm{C}$ until the samples could be analysed for isotopic abundance and metabolic concentrations.

\footnotetext{
Analysis of ${ }^{15} \mathbf{N}$

${ }^{15} \mathrm{NH}_{3}$ was measured by a variation of a method that we have described previously (Nissim et al., 1981). To small $(0.2 \mathrm{ml})$ columns of AG-50 (X8; 50-100 mesh; $\mathrm{H}^{+}$ form) in disposable Pasteur pipettes was added $5 \mathrm{ml}$ of $1 \mathrm{M}-\mathrm{NaOH}$ that had been boiled for $15 \mathrm{~min}$ to eliminate all traces of $\mathrm{NH}_{3}$. The $\mathrm{NaOH}$, which was allowed to cool before use, was removed by washing each column with $5 \mathrm{ml}$ of deionized water that had been boiled for $30 \mathrm{~min}$ and allowed to cool. After the addition of $0.5 \mathrm{ml}$ of the neutralized $\mathrm{HClO}_{4}$ extract, each column was washed with $5 \mathrm{ml}$ of boiled deionized water that had been allowed to cool. The ${ }^{15} \mathrm{NH}_{3}$ was eluted from the columns with $2 \mathrm{ml}$ of $10 \mathrm{~mm}-\mathrm{NaOH}$ that had been prepared immediately before use from the boiled $\mathrm{NH}_{3}$-free $1 \mathrm{M}-\mathrm{NaOH}$ and water. The $\mathrm{NH}_{3}$ was eluted into test tubes containing $2 \mathrm{ml}$ of $0.1 \mathrm{M}$-sodium phosphate buffer, $\mathrm{pH} 7.0$, containing $34 \mu \mathrm{M}-\mathrm{NADH}$ and 5 units of glutamate dehydrogenase/ ml. $\mathrm{NH}_{3}$ was eliminated from the sodium phosphate
}

buffer by stirring $100 \mathrm{ml}$ for $30 \mathrm{~min}$ with $50 \mathrm{ml}$ of AG-50 (X8; 16-50 mesh; $\mathrm{Na}^{+}$form). Before use this cationexchange resin was stirred for $30 \mathrm{~min}$ in boiled $1 \mathrm{M}-\mathrm{NaOH}$ and then washed until neutral in boiled deionized water. Both the NADH and glutamate dehydrogenase solutions were prepared in the treated sodium phosphate buffer and used within $1 \mathrm{~h}$.

As the ${ }^{15} \mathrm{NH}_{3}$ was eluted from the columns the test tubes were gently swirled to ensure mixing of the $10 \mathrm{~mm}-\mathrm{NaOH}$ phase with the denser $0.1 \mathrm{M}$-sodium phosphate buffer phase. The test tubes then were covered and immediately placed in a water bath at $37^{\circ} \mathrm{C}$ for $15 \mathrm{~min}$, after which the tubes were placed on ice and sufficient $1.5 \mathrm{M}-\mathrm{HCl}$ was added to adjust the $\mathrm{pH}$ to 4-5. The total contents of each test tube then were applied to columns $(0.5 \mathrm{~cm} \times 7 \mathrm{~cm})$ of AG-50 (X8; 100-200 mesh; $\mathrm{H}^{+}$form). After the column had been washed with $5 \mathrm{ml}$ of water, the $\left[{ }^{15} \mathrm{~N}\right]$ glutamate formed from the ${ }^{15} \mathrm{NH}_{3}$ was eluted with $4 \mathrm{ml}$ of $4 \mathrm{M}-\mathrm{NH}_{3}$. The eluate was dried at $70^{\circ} \mathrm{C}$ under $\mathrm{N}_{2}$, and the n-butyl $N$-trifluoroacetylglutamate derivative was prepared (Nissim et al., 1981). G.c.-m.s. analysis of the $m / z 199 / 198$ ratio was done as described previously (Nissim et al., 1981).

$\left[{ }^{15} \mathrm{~N}\right]$ Glutamine in the $\mathrm{HClO}_{4}$ extract was analysed after application of the neutralized extract to a column $(0.5 \mathrm{~cm} \times 7 \mathrm{~cm})$ of AG-50 (X8; 100-200 mesh; $\mathrm{H}^{+}$form) and subsequent elution with $4 \mathrm{M}-\mathrm{NH}_{3}$. The $N$-trifluoroacetyl derivative was formed and isotopic abundance of the amino and amide nitrogen atoms was measured from the $m / z 182 / 181$ and $m / z 112 / 111$ ratios in accordance with a method that we have described elsewhere (Nissim et al., 1984).

Isotopic enrichment of $\left[{ }^{15} \mathrm{~N}\right]$ alanine was measured after isolation of this amino acid from an AG-50 column as described above. The n-buty $1 N$-trifluoroacetyl derivative was formed as described by Roach \& Gehrke (1969). The $m / z 141 / 140$ ratio was measured with selected ion monitoring.

In order to determine isotopic abundance in $\left[{ }^{15} \mathrm{~N}\right]$ glutamate and $\left[{ }^{15} \mathrm{~N}\right]$ aspartate, these amino acids were separated from glutamine and asparagine by adding $1 \mathrm{ml}$ of the neutralized $\mathrm{HClO}_{4}$ extract to $2 \mathrm{ml}$ of $0.1 \mathrm{M}$-Tris/ $\mathrm{HCl}$ buffer, $\mathrm{pH} 6.7$, and applying this mixture to a column $(0.5 \mathrm{~cm} \times 2.5 \mathrm{~cm})$ of AG-1 $(\mathrm{X} 8 ; 200-400$ mesh; $\mathrm{Cl}^{-}$form). The columns were then washed with $3 \mathrm{ml}$ of deionized water, and the glutamate and aspartate were eluted with $3 \mathrm{ml}$ of $1 \mathrm{M}-\mathrm{HCl}$. Enrichment in $\left[{ }^{15} \mathrm{~N}\right]$ glutamate and $\left[{ }^{15} \mathrm{~N}\right]$ aspartate was measured in the respective n-butyl $N$-trifluoroacetyl derivatives from the $m / z 255 / 254$ and $m / z$ 185/184 ratios.

Isotopicabundancein [6-amino- $\left.{ }^{15} \mathrm{~N}\right]$ adeninenucleotides was measured by a method that we have described elsewhere (Lewis \& Yudkoff, 1985). After isolation of the nucleotide fraction with a $3 \mathrm{ml}$ SAX (Baker) column and acid hydrolysis of this fraction to adenine, the latter was isolated with a $3 \mathrm{ml} \mathrm{C}-18$ column (Baker) and the di-t-butyl dimethylsilyl derivative was prepared. G.c.-m.s. conditions were as previously described (Lewis \& Yudkoff, 1985). Isotopic enrichment was determined from the $m / z 307 / 306$ ratio.

\section{Analytical methods}

Amino acids were measured as the $o$-phthalaldehyde derivative with reverse-phase liquid chromatography (Jones \& Gilligan, 1983). S-Methylcysteine was used as an internal standard. 


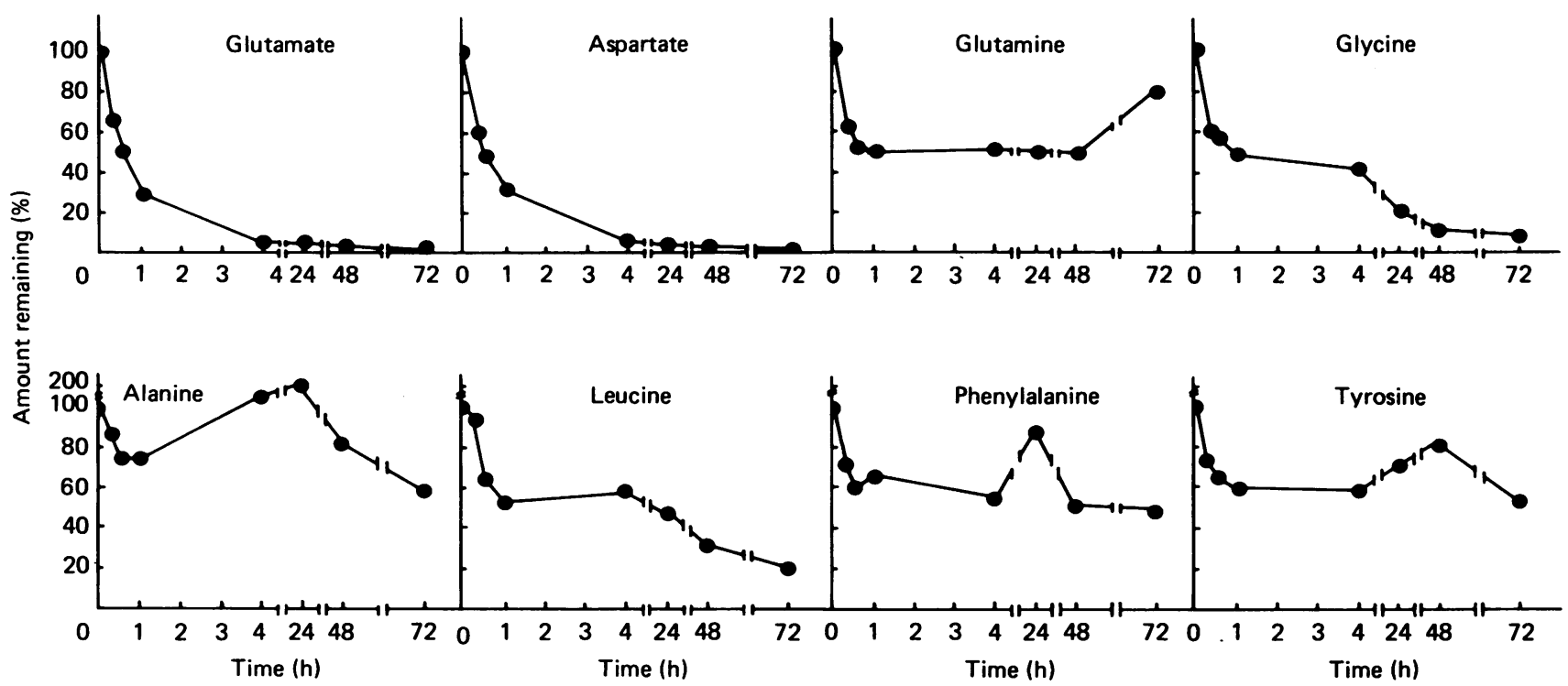

Fig. 1. Amino acid concentrations in medium in which astrocytes were cultured

'Steady-state' incubation medium was removed from the cultured astrocytes and replaced with 2 ml of fresh medium. At the indicated times $20 \mu \mathrm{l}$ portions of this medium were removed and analysed for amino acid concentration, as described in the Materials and methods section. Results are expressed as percentages of initial concentration in the medium. Each point is the mean for two experiments.

Ammonia, lactate, pyruvate and adenine nucleotides were measured enzymically (Lowry \& Passonneau, 1972).

Protein was determined with the Coomassie Blue method (Bradford, 1976).

\section{Calculations}

Isotopic abundance (atom \% excess) was calculated from the formula of Biemann (1962). Flux was determined from the product of the isotopic abundance/100 and metabolite concentration over time.

\section{RESULTS}

\section{Medium and intracellular amino acid concentrations}

Fig. 1 shows amino acid concentrations after replacement of the 'steady-state' culture medium with fresh medium. The disappearance of most compounds was fairly rapid, declining to approx. $70 \%$ of the initial concentration by $1 \mathrm{~h}$, after which concentrations remained stable or fell slowly over the ensuing 3 days. The pattern of glutamate and aspartate disappearance was quite different because the concentrations of both amino acids declined progressively to very low values, by $4 \mathrm{~h}$ falling to less than $10 \mu \mathrm{M}$. The glutamate and aspartate data points could be fitted closely to single-exponential decay curves with fractional turnover constants for each of $0.015 \mathrm{~min}^{-1}$, corresponding to initial disappearance rates from the medium of approx. $12.9 \mathrm{nmol} / \mathrm{min}$ per $\mathrm{mg}$ of protein. Of interest was the observation that apparent net synthesis of alanine occurred, reaching a maximum in the medium by $24 \mathrm{~h}$ and declining slowly thereafter.

The final, steady-state, amino acid concentrations in medium and astrocytes are shown in Table 1. The concentrations of glutamate, aspartate and glycine, all of which are putative neurotransmitters, were very low in the 'steady-state' medium. The initial concentration of
Table 1. Steady-state amino acid concentrations in cultured astrocytes and medium

Cells were cultured as described in the Materials and methods section. The incubation medium was modified Ham's F-12 medium (Kim et al., 1983). At 4 days after the addition of glial growth factor, when astrocytes had been 9 days in culture, the medium $(2 \mathrm{ml})$ was removed and cells were quickly washed once with cold $140 \mathrm{~mm}-\mathrm{NaCl} / 5 \mathrm{~mm}$ sodium phosphate buffer, pH 7.4. Then $2 \mathrm{ml}$ of $10 \mathrm{~mm}-\mathrm{HCl}$ was added and cells were frozen and thawed three times to liberate intracellular contents. Amino acids in cells and medium were determined by h.p.l.c. after the formation of fluorescent o-phthalaldehyde derivatives. Results are means \pm S.D. for four experiments.

\begin{tabular}{ccc}
\hline $\begin{array}{c}\text { Amino } \\
\text { acid }\end{array}$ & $\begin{array}{c}\text { Concn. in } \\
\text { cell }(\mathrm{nmol} / \mathrm{mg})\end{array}$ & $\begin{array}{c}\text { Concn. in } \\
\text { medium }(\mathrm{nmol} / \mathrm{ml})\end{array}$ \\
\hline Glu & $26.9 \pm 11.0$ & $3.5 \pm 0.6$ \\
Asp & $9.4 \pm 5.3$ & $6.4 \pm 3.0$ \\
Ser & $28.0 \pm 13.0$ & $97.7 \pm 29.0$ \\
Gln & $119.5 \pm 60.4$ & $833.9 \pm 148.1$ \\
His & $20.8 \pm 16.3$ & $202.1 \pm 37.5$ \\
Gly & $25.7 \pm 14.7$ & $44.0 \pm 22.1$ \\
Thr & $44.7 \pm 18.8$ & $283.9 \pm 38.2$ \\
Arg & $76.3 \pm 32.6$ & $1072.6 \pm 259.6$ \\
Ala & $28.0 \pm 15.9$ & $269.9 \pm 77.8$ \\
Tyr & $14.7 \pm 8.0$ & $156.4 \pm 23.7$ \\
Phe & $14.6 \pm 7.7$ & $165.1 \pm 21.4$ \\
Ile & $13.1 \pm 7.4$ & $161.1 \pm 41.3$ \\
Leu & $15.6 \pm 6.8$ & $234.4 \pm 95.3$ \\
Orn & $14.9 \pm 12.1$ & $59.6 \pm 31.1$ \\
Lys & $34.1 \pm 20.2$ & $502.0 \pm 182.6$ \\
\end{tabular}

these amino acids was $0.1 \mathrm{~mm}$. The concentrations in the medium of most other amino acids also were lower than the initial value, although to a lesser extent. The only 

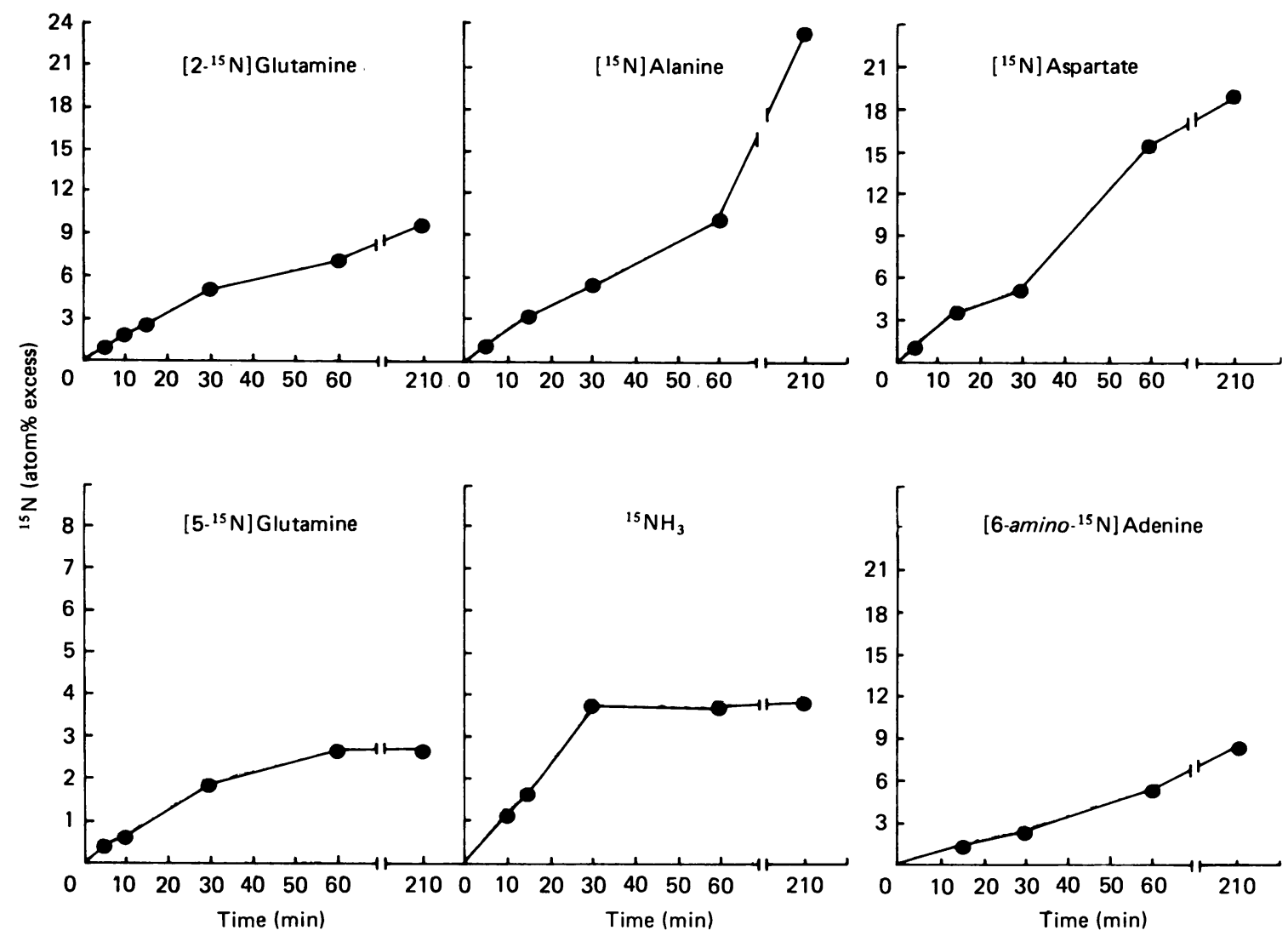

Fig. 2. Isotopic abundance of ${ }^{15} \mathbf{N}$ in selected metabolites in cultured astrocytes

[15 N]Glutamate $(0.25 \mathrm{mM})$ was added to 'steady-state' culture medium containing cultured astrocytes. At the indicated times $\mathrm{HClO}_{4}$ was added and ${ }^{15} \mathrm{~N}$ isotopic abundance was determined in neutralized extracts as described in the Materials and methods section. Results are expressed as atom\% excess versus time. Each point is the mean for three experiments.

compound that increased in concentration was alanine, indicating net synthesis by the astrocytes.

Although very little glutamate was present in the medium, the intracellular steady-state glutamate concentration was as high as those of most other amino acids. The most abundant intracellular amino acid was glutamine, the concentration of which was more than 4-fold greater than that of glutamate (Table 1).

\section{Transfer of ${ }^{15} \mathrm{~N}$ from L- $\left[{ }^{15} \mathrm{~N}\right] \mathrm{glutamate}$}

Fig. 2 shows the enrichment (atom\% excess) of ${ }^{15} \mathrm{~N}$ in selected metabolites after the addition of $0.25 \mathrm{~mm}-\mathrm{L}-$ $\left[{ }^{15} \mathrm{~N}\right]$ glutamate to the 'steady-state' culture medium. Isotopic abundance in $\left[2-{ }^{15} \mathrm{~N}\right]$ glutamine continued to increase during the $210 \mathrm{~min}$ observation period, reaching approx. 10.0 atom \% excess. In contrast, enrichment in $\left[5-{ }^{15} \mathrm{~N}\right]$ glutamine tended towards a plateau, suggesting more rapid turnover of the amide nitrogen compared with the amino nitrogen. Formation of $\left[5-{ }^{15} \mathrm{~N}\right]$ glutamine reflects production of ${ }^{15} \mathrm{NH}_{3}$ from $\left[{ }^{15} \mathrm{~N}\right]$ glutamate and subsequent ${ }^{15} \mathrm{~N}$ incorporation into the amide moiety via the glutamine synthetase reaction. The observed enrichment in ${ }^{15} \mathrm{NH}_{3}$, which exceeded that in $\left[5^{-15} \mathrm{~N}\right]$ glutamine, is consistent with such a precursor-product relationship. At $30 \mathrm{~min}$, the ${ }^{15} \mathrm{NH}_{3}$ isotopic abundance was approx. 3.5 atom $\%$ excess, compared with approx. 2.5 atom $\%$ excess for $\left[5-{ }^{15} \mathrm{~N}\right]$ glutamine.

The significance of transamination reactions in astrocytes has been questioned ( $\mathrm{Yu}$ et al., 1982). The present data show unequivocally, however, that there occurs a transfer of nitrogen from glutamate to both alanine and aspartate. Indeed, as shown in Fig. 2, the formation of both $\left[{ }^{15} \mathrm{~N}\right]$ alanine and $\left[{ }^{15} \mathrm{~N}\right]$ aspartate occurred as rapidly as that of $\left[2-^{15} \mathrm{~N}\right]$ glutamine. Enrichment in neither compound was observed to attain a plateau, even after an incubation of $210 \mathrm{~min}$ with $\left.{ }^{15} \mathrm{~N}\right]$ glutamate. The 'steady-state' $\left[{ }^{15} \mathrm{~N}\right]$ glutamate enrichment was approx. 35.0 atom $\%$ excess (detailed results not shown).

It also is evident from the data in Fig. 2 that there is measurable ${ }^{15} \mathrm{~N}$ in the 6 -amino position of the adenine nucleotides. This nitrogen must reflect adenylosuccinate formation from IMP and $\left[{ }^{15} \mathrm{~N}\right]$ aspartate via the purine nucleotide cycle (Lowenstein, 1972), with cleavage of the labelled adenylosuccinate by adenylosuccinase to form [6-amino-15N]AMP. Since phosphorylation of AMP to produce ADP and ATP occurs much more rapidly than the synthesis of adenylosuccinate and AMP (Krebs et al., $1978)$, the isotopic enrichment in [6-amino- $\left.{ }^{-15} \mathrm{~N}\right]$ adenine illustrated in Fig. 2 refers to ${ }^{15} \mathrm{~N}$ present in the 6-amino position of all three adenine nucleotides (Krebs et al., 1978). As would be expected, isotopic abundance in $\left[{ }^{15} \mathrm{~N}\right]$ aspartate exceeded that in $\left[6-\right.$ amino- $\left.^{15} \mathrm{~N}\right]$ adenine, the latter having been derived from aspartate $\mathbf{N}$. After 210 min incubation, ${ }^{15} \mathrm{~N}$ in the adenine nucleotides was approx. 8.0 atom $\%$ excess. 

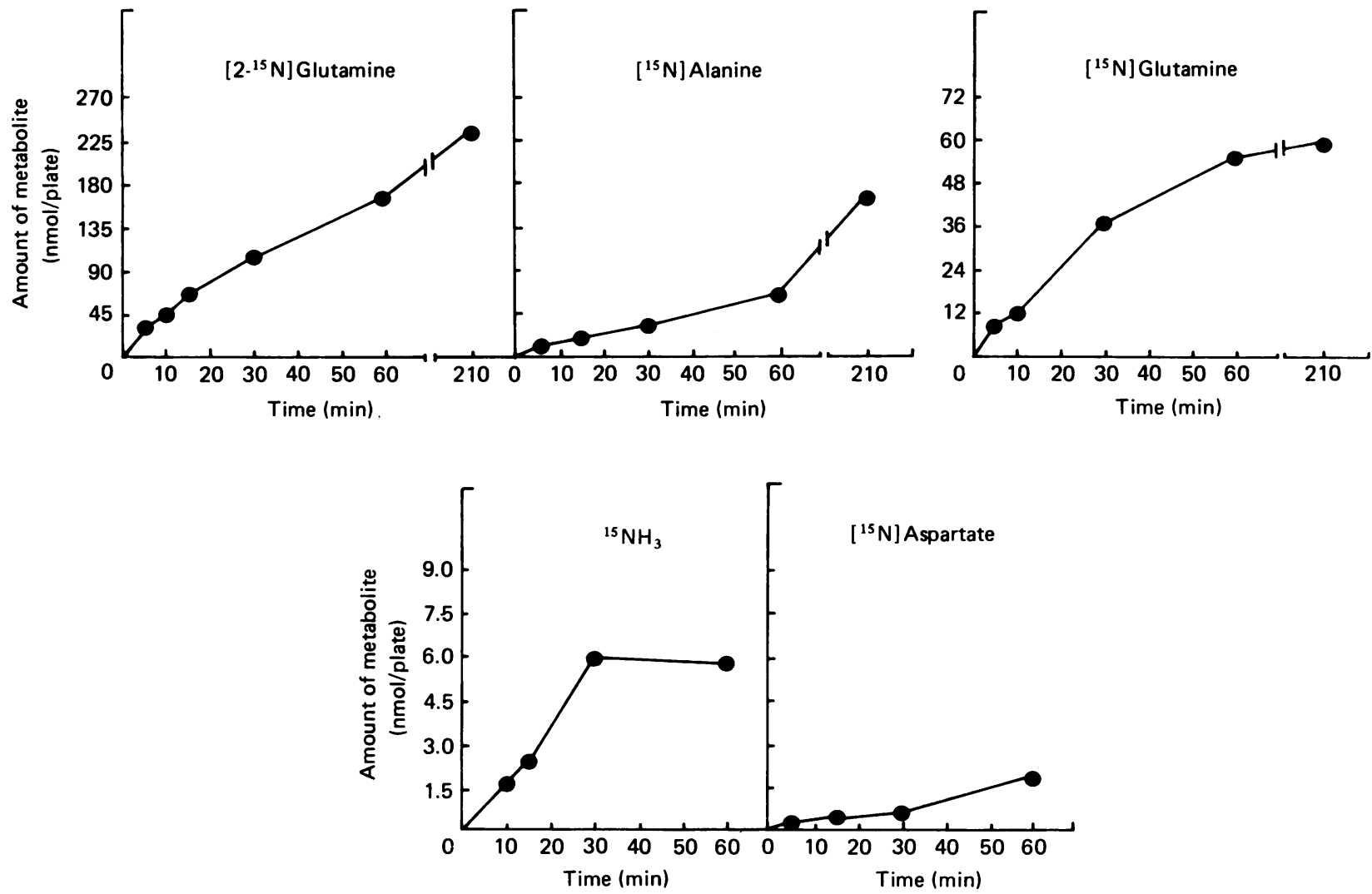

Fig. 3. Amount of ${ }^{15} \mathrm{~N}$-labelled metabolites in astrocyte cultures

Incubation conditions were as described in the legend to Fig. 2 and in the Materials and methods section. The amount of ${ }^{15} \mathrm{~N}$ in the indicated metabolites represents product of isotopic abundance (atom \% excess/100) and total amount of metabolite in each culture plate (nmol/plate). Each point is the mean for three experiments.

Fig. 3 shows the rates of flux of glutamate $\mathrm{N}$ into the $\alpha$ and amide nitrogen atoms of glutamine, alanine and $\mathrm{NH}_{3}$. These rates represent the product of isotopic abundance and metabolite concentration and are expressed as nmol of ${ }^{15} \mathrm{~N}$ per astrocyte culture. Table 2 shows the rates of flux as determined from the linear portion of the curves shown in Fig. 3. Results are normalized to the tissue protein. Also shown in Table 2 is the fraction $(\%)$ of the $\left[{ }^{15} \mathrm{~N}\right]$ glutamate added to the system that was present in a given metabolite after $210 \mathrm{~min}$ incubation. By this time approx. $90 \%$ of the labelled glutamate had been converted into glutamine, alanine, $\mathrm{NH}_{3}$ or aspartate. About one-half of glutamate $\mathrm{N}$ was recovered in either the $\alpha$ or the amide nitrogen atoms of glutamine and about one-third in alanine nitrogen atoms.

\section{Transfer of ${ }^{15} \mathrm{~N}$ from alanine and glutamine to glutamate}

The data presented above illustrate the transfer of nitrogen atoms from glutamate to amino acids, $\mathrm{NH}_{3}$ and adenine nucleotides. Although appreciable flux from glutamate $\mathbf{N}$ to other compounds was noted, the intra-astrocyticglutamateconcentration is high, especially when compared with the glutamate concentration in the medium (Table 1). This fact suggests substantial astrocyte glutamate synthesis. In order to identify some of the nitrogen sources for the glutamate so produced, cells were incubated for $24 \mathrm{~h}$ in the presence of $\left[{ }^{15} \mathrm{~N}\right]$ alanine, $\left[2^{-15} \mathrm{~N}\right]$ glutamine or $\left[5^{15} \mathrm{~N}\right]$ glutamine, and
Table 2. Rates of flux from $\left[{ }^{15} \mathrm{~N}\right]$ glutamate to other metabolites in cultured astrocytes

Astrocytes were cultured as described in the Materials and methods section. Experiments were initiated by the addition of $\left[{ }^{15} \mathrm{~N}\right]$ glutamate (concentration in medium $=0.25 \mathrm{~mm}$ ). At selected times $\mathrm{HClO}_{4}$ was added. Metabolite concentrations and ${ }^{15} \mathrm{~N}$ isotopic abundance in these metabolites were determined as described in the Materials and methods section. Amount of ${ }^{15} \mathrm{~N}$ in a metabolite represents the product of isotopic abundance (atom\% excess/100) and metabolite concentration (nmol/mg of protein) for each time point. Flux was estimated from the linear portion of the curves shown in Fig. 3. Results are means for three experiments.

Flux

(nmol/min Amount of added ${ }^{15} \mathrm{~N}$ per $\mathrm{mg})$ in product at $210 \mathrm{~min}(\%)$

Glu $\rightarrow\left[{ }^{15} \mathrm{~N}\right] \mathrm{Ala}$
$\mathrm{Glu} \rightarrow\left[2-{ }^{15} \mathrm{~N}\right] \mathrm{Gln}$
$\mathrm{Glu} \rightarrow[5-15 \mathrm{~N}] \mathrm{Gln}$
$\mathrm{Glu} \rightarrow{ }^{15} \mathrm{NH}_{3}$
$\mathrm{Glu} \rightarrow\left[{ }^{15} \mathrm{~N}\right] \mathrm{Asp}$

3.93

9.01

4.24

0.57

0.07

31.8

45.6

11.6

1.2

0.4

isotopic abundance in both $\left[{ }^{15} \mathrm{~N}\right]$ glutamate and the indicated precursor was measured. Results are shown in Table 3. With $\left[{ }^{15} \mathrm{~N}\right]$ alanine as precursor, enrichment in 
Table 3. Isotopic abundance (atom $\%$ excess) in $\left[{ }^{15} \mathrm{~N}\right] g l u t a m a t e$ in cultured astrocytes, with [ $\left.{ }^{15} \mathrm{~N}\right]$ alanine, $\left[2-{ }^{15} \mathrm{~N}\right]$ glutamine or $\left[5^{-15} \mathrm{~N}\right]$ glutamine as precursor

Cells were cultured as described in the Materials and methods section. Experiments were initiated by addition of indicated ${ }^{15} \mathrm{~N}$-labelled precursor to culture dish. After $24 \mathrm{~h}$ incubation, $\mathrm{HClO}_{4}$ was added and ${ }^{15} \mathrm{~N}$ isotopic abundance of each metabolite was determined as described in the Materials and methods section. I-Pre and I-Glu refer to ${ }^{15} \mathrm{~N}$ isotopic abundance of the precursor and $\mathrm{L}-\left[{ }^{15} \mathrm{~N}\right]$ glutamate respectively. $100 \times \mathrm{I}-\mathrm{Glu} / \mathrm{I}-\mathrm{Pre}$ refers to the fraction $(\%)$ of $\left[{ }^{15} \mathrm{~N}\right]$ glutamate derived from the indicated precursor. Results represent means \pm S.D. for four experiments.

\begin{tabular}{lrcl}
\hline Precursor & \multicolumn{1}{c}{ I-Pre } & I-Glu & $(100 \times$ I-Glu/I-Pre $)$ \\
\hline$\left.{ }^{15} \mathrm{~N}\right] \mathrm{Ala}$ & $5.8 \pm 1.7$ & $1.8 \pm 0.3$ & $32.9 \pm 12.6$ \\
{$\left[{ }^{2-15} \mathrm{~N}\right] \mathrm{Gln}$} & $15.9 \pm 0.8$ & $4.9 \pm 1.3$ & $30.3 \pm 7.8$ \\
{$\left[5-{ }^{15} \mathrm{~N}\right] \mathrm{Gln}$} & $21.1 \pm 3.1$ & $2.5 \pm 0.9$ & $12.5 \pm 4.9$ \\
\hline
\end{tabular}

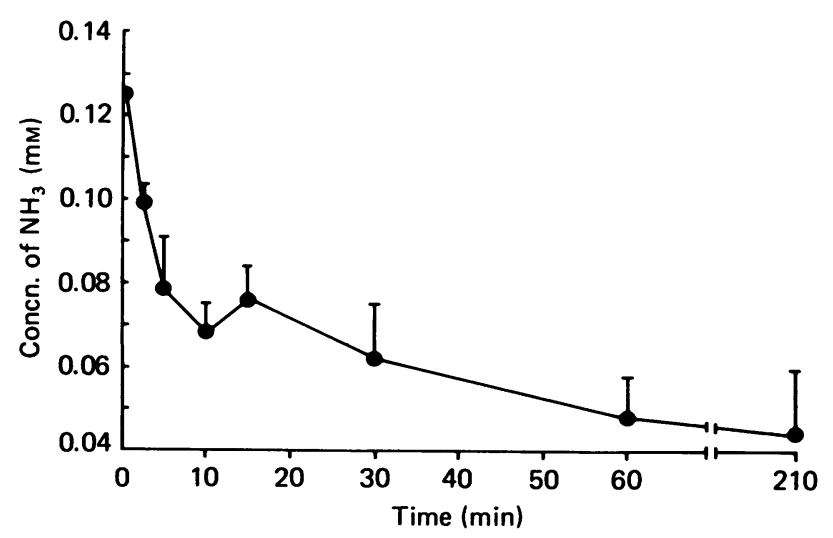

Fig. 4. Concentration of $\mathrm{NH}_{3}$ in the medium containing cultured astrocytes after addition of $0.25 \mathrm{mM}-\mathrm{L}$-glutamic acid

Medium was removed at the indicated times and $\mathrm{NH}_{3}$ was determined as described in the Materials and methods section. Each point is the mean \pm S.D. for four experiments.

glutamate and alanine was approx. 2.0 and 6.0 atom $\%$ excess, respectively, indicating that almost one-third of glutamate $\mathbf{N}$ was derived from alanine. When cells were incubated with $\left[2-{ }^{15} \mathrm{~N}\right]$ glutamine, about $30 \%$ of glutamate $\mathrm{N}$ appeared to have been derived from the $\alpha$-amino group of glutamine. Experiments with [5-15 N]glutamine showed that the amide moiety donated $12.5 \%$ of glutamate $\mathrm{N}$ via synthesis from 2-oxoglutarate.

\section{Effects of glutamate on the concentrations of ammonia and ATP}

The above data are consistent with a pivotal role for the glutamine synthetase pathway in astrocyte glutamate metabolism. It has been suggested (Berl, 1966) that this reaction is important for brain $\mathrm{NH}_{3}$ detoxification, although a definite decline of astrocyte $\mathrm{NH}_{3}$ concentration secondary to glutamine synthetase activity has not been documented. The data in Fig. 4 indicate that addition of $\left[{ }^{15} \mathrm{~N}\right]$ glutamate to the culture medium does result in a net decline of $\mathrm{NH}_{3}$ concentrations. The concentration of $\mathrm{NH}_{3}$ in the medium fell promptly after glutamate addition and remained low, the mean concentration at $60 \mathrm{~min}$ being approx. $55 \%$ of the basal value.

Addition of $\left[{ }^{15} \mathrm{~N}\right]$ glutamate did not affect ATP concentrations, which remained at approx. $30-40 \mathrm{nmol} / \mathrm{mg}$ of protein.

\section{DISCUSSION}

The current data identify three pathways of astrocyte glutamate $\mathbf{N}$ metabolism: (1) glutamine synthesis, involving transfer of glutamate $\mathrm{N}$ to both amino and amide moieties; (2) transamination with pyruvate to yield alanine; (3) transamination with oxaloacetate to yield aspartate, the nitrogen atoms of which are transferred in part to the 6-amino group of the adenine nucleus via the purine nucleotide cycle. As shown in Table 2, virtually all added ${ }^{15} \mathrm{~N}$ could be recovered in one of these metabolites.

The current data (Fig. 1) also confirm avid astrocyte glutamate utilization, even in the presence of other amino acids. Such demonstration is important, since studies of astrocyte glutamate metabolism usually employ an incubation medium devoid of amino acids other than glutamate (Logan \& Snyder, 1972; Henn et al., 1974; Ramaharobandro et al., 1982; Drejer et al., 1982; Gordon \& Balázs, 1983). Indeed, the current data document relatively intense simultaneous disappearance of aspartate and glycine from the medium, as well as glutamate (Table 1). Each of these amino acids is a neurotransmitter, and the rapidity with which astrocytes remove them from the incubation medium may reflect the role glia play as maintainer of a low 'background' concentration of biologically active compounds.

Much glutamate $\mathbf{N}$ enters the glutamine synthetase pathway, which is very prominent in astrocytes (Norenberg, 1979; Norenberg \& Martinez-Hernandez, 1979). Flux through glutamine synthetase was approx. $9.0 \mathrm{nmol} / \mathrm{min}$ per $\mathrm{mg}$, a higher value than that noted in studies utilizing [ ${ }^{14} \mathrm{C}$ ]glutamate (Yu et al., 1982, 1984; Hertz et al., 1983). The difference may reflect the higher glutamate concentration in the medium used in the present study $(0.25 \mathrm{~mm}$ versus $0.05 \mathrm{~mm})$. As indicated in Fig. 4, formation of glutamine serves to lower the concentration of $\mathrm{NH}_{3}$, which is neurotoxic in high concentration. In contrast, the concentration of ATP, like $\mathrm{NH}_{3}$ a reactant in the glutamine synthetase pathway, remained constant. The astrocyte ATP concentration is $30-40 \mathrm{nmol} / \mathrm{mg}$ of protein, and glutamine synthesis, which consumes ATP on a molar basis, proceeds at approx. $4.0 \mathrm{nmol} / \mathrm{min}$ per $\mathrm{mg}$ of protein (Table 2). Thus the constancy of ATP concentrations after $\left[{ }^{15} \mathrm{~N}\right]$ glutamate addition implies very efficient mechanisms for maintenance of energy reserve despite rapid ATP consumption.

Astrocytes clearly possess glutaminase activity as well as glutamine synthetase activity. As shown in Table 3, the $\left[{ }^{15} \mathrm{~N}\right]$ glutamate/[2-15N]glutamine ratio was approx. 0.3:1.0 when glutamine labelled in the amino $\mathrm{N}$ was precursor. With L-[5-15 $\mathrm{N}]$ glutamine as precursor, significant labelling was noted again in $\left[{ }^{15} \mathrm{~N}\right]$ glutamate, reflecting glutaminase activity and subsequent reductive amination of 2-oxoglutarate via the glutamate dehydrogenase pathway. That the glutamate dehydrogenase reaction also may function in the direction of oxidative deamination of glutamate is proved by the formation of both ${ }^{15} \mathrm{NH}_{3}$ and $\left[5-{ }^{15} \mathrm{~N}\right]$ glutamine when cells are incubated with $\left[{ }^{15} \mathrm{~N}\right]$ glutamate (Fig. 2). The only other 
potential source of $\mathrm{NH}_{3}$ under these conditions would have been via the purine nucleotide cycle, but this could not have been the sole source, given the higher isotopic abundance in ${ }^{15} \mathrm{NH}_{3}$ compared with [6-amino- $\left.{ }^{15} \mathrm{~N}\right]$ adenine (Fig. 2). The current data only demonstrate the bi-directionality of the glutamate dehydrogenase reaction. No inference with regard to net flux is possible. Factors regulating this important pathway in astrocytes have been reviewed elsewhere (Yu et al., 1982).

The second major metabolic fate of glutamate $\mathrm{N}$, after glutamine formation, is alanine synthesis. Enrichment of $\left[{ }^{15} \mathrm{~N}\right]$ alanine even exceeded that in $\left[2-{ }^{15} \mathrm{~N}\right]$ glutamine (Fig. 2 ), and the estimated flux of nitrogen atoms from glutamate to alanine was approx. $70 \%$ of the flux to the amino $\mathrm{N}$ of glutamine (Table 2). Two isoenzymes of alanine aminotransferase, cytosolic and mitochondrial, have been identified in bovine brain (Ruscak et al., 1982). Both isoenzymes show a low $K_{\mathrm{m}}$ value for glutamate, but the $K_{\mathrm{m}}$ for alanine is much greater for the cytosolic protein (Ruscak et al., 1982). This factor could account for net alanine synthesis, since the equilibrium of the cytosolic alanine aminotransferase pathway would be towards alanine production, given the greater avidity of the cytosolic enzyme for glutamate. The fact that pyruvate, which would react with glutamate to form alanine, is present at a greater cytosolic concentration than 2-oxoglutarate also would favour synthesis of alanine rather than glutamate (Figs. 2 and 3). The metabolic fate of alanine synthesized by astrocytes is uncertain. One possibility is that this alanine is utilized by neurons to synthesize glutamate, which then is utilized as a neurotransmitter. The glutamine produced by astrocytes is used by neurons to produce glutamate in the glutamine-glutamate cycle (Van den Berg et al., 1976; Shank \& Aprison, 1981). An alanine-glutamate cycle between astrocytes and neurons also may exist. Additional studies with $\left[{ }^{15} \mathrm{~N}\right]$ alanine in cultured neurons or synaptosomes may help to clarify the importance of alanine to neuronal glutamate synthesis.

Although net alanine synthesis was noted, the data show that the astrocyte alanine aminotransferase pathway can function in the direction of glutamate production. Thus, when the cells were incubated for $24 \mathrm{~h}$ with $\left[{ }^{15} \mathrm{~N}\right]$ alanine, isotopic abundance in $\left[{ }^{15} \mathrm{~N}\right]$ glutamate was $30 \%$ of that observed in $\left[{ }^{15} \mathrm{~N}\right]$ alanine (Table 3 ). Considerable cycling of nitrogen atoms occurs in these cells, as is evidenced also by synthesis of glutamate from glutamine (Table 3). Substrate cycling may allow the astrocyte to respond to a broad range of metabolic conditions. Thus alanine synthesis is an important mechanism for disposal of glutamate N. Conversely, when glutamate concentrations are low, perhaps because of rapid utilization in the glutamine synthetase pathway when $\mathrm{NH}_{3}$ production is high, flux from alanine back to glutamate would help maintain intracellular concentrations of the latter amino acid.

Transfer of nitrogen atoms from glutamate to aspartate also occurs, but the rate is low compared with flux towards either glutamine or alanine (cf. Table 2). The aspartate aminotransferase pathway is extremely active in astroglia, with a specific activity 5-10 times that of glutamine synthetase (Hertz et al., 1983). As indicated in Fig. 2, some aspartate $\mathrm{N}$ is transferred to the 6-amino position of the adenine nucleotides, presumably via the purine nucleotide cycle (Lowenstein, 1972; Schultz \& Lowenstein, 1978), the function of which has been demonstrated in brain slices (Schultz \& Lowenstein, 1978), but not previously in cultured astrocytes. The exact function of the purine nucleotide cycle in these cells cannot be inferred from these data. In skeletal muscle the cycle is important to the maintenance of ATP concentrations (Lowenstein, 1972), and inhibition of the cycle impairs muscle function (Swain et al., 1984). Although the purine nucleotide cycle does not appear to be quantitatively important in astrocytes for the disposal of glutamate $\mathbf{N}$, it may abet overall energy metabolism and thereby ensure the constant supply of ATP needed for the glutamine synthetase reaction.

This work was supported by Research Grants HD08536 and NS17752 from the National Institutes of Health.

\section{REFERENCES}

Baldessarini, R. J. \& Yorke, C. (1974) J. Neurochem. 23, 839-848

Berl, S. (1966) Biochemistry 5, 916-922

Berl, S., Takagaki, G., Clarke, D. D. \& Waelsch, H. (1962) J. Biol. Chem. 237, 2562-2569

Biemann, K. (1962) in Organic Chemical Applications (Biemann, K., ed.), pp. 223-227, McGraw-Hill, New York.

Bradford, H. G. \& Ward, H. K. (1976) Brain Res. 110, 115-125

Bradford, M. M. (1976) Anal. Biochem. 72, 248-254

Cooper, A. J. L., McDonald, J. M., Gelbard, A. S., Gledhill, R. F. \& Duffy, T. E. (1979) J. Biol. Chem. 254, 4982-4991

Drejer, J., Larsson, O. M. \& Schousboe, A. (1982) Exp. Brain Res. 47, 259-269

Freed, B. R. \& Gelbard, A. S. (1980) Can. J. Physiol. Pharmacol. 60, 60-67

Gordon, R. D. \& Balázs, R. (1983) J. Neurochem. 40, 1090-1099

Henn, F. A., Goldstein, M. N. \& Hamberger, A. (1974) Nature (London) 249, 663-664

Hertz, L., Yu, A. C. H., Potter, R. L., Fisher, T. E. \& Schousboe, A. (1983) in Glutamine, Glutamate and GABA in the Central Nervous System (Hertz, L., Kvamme, E., McGeer, E. G. \& Schousboe, A., eds.), pp. 327-342, Alan Liss, New York

Jones, B. \& Gilligan, J. P. (1983) J. Chromatogr. 266, 471-482

Kim, S. U., Stern, J., Kim, M. W. \& Pleasure, D. E. (1983) Brain Res. 274, 79-86

Krebs, H. A., Hems, R. \& Lund, P. (1978) Biochem. J. 176, 733-737

Lewis, S. \& Yudkoff, M. (1985) Anal. Biochem. 145, 354-361

Lockwood, A. H., McDonald, J. M., Reiman, R. E., Gelbard, A. S., Laughlin, J. S., Duffy, T. E. \& Plum, F. (1979) J. Clin. Invest. 63, 449-460

Logan, W. J. \& Snyder, S. H. (1972) Brain Res. 42, 413-431

Lowenstein, J. M. (1972) Physiol. Rev. 52, 384-414

Lowry, O. H. \& Passonneau, J. V. (1972) A Flexible System of Enzymatic Analysis, pp. 194-199, 212-216, 147-149, 153, Academic Press, New York

Nissim, I., Yudkoff, M., Yang, W., Terwilliger, T. \& Segal, S. (1981) Anal. Biochem. 114, 125-130

Nissim, I., Yudkoff, M. \& Lapidot, A. (1984) Anal. Biochem. $143,14-20$

Norenberg, M. D. (1979) J. Histochem. Cytochem. 27, 756-762 Norenberg, M. D. \& Martinez-Hernandez, A. (1979) Brain Res. 161, 303-310

Ramaharobandro, N., Borg, J., Mandel, P. \& Mark, J. (1982) Brain Res. 244, 113-121

Roach, D. \& Gehrke, C. W. (1969) J. Chromatogr. 44, 269-278

Ruscak, M., Orlicky, J., Zubor, V. \& Hager, H. (1982) J. Neurochem. 39, 210-216

Schultz, V. \& Lowenstein, J. M. (1978) J. Biol. Chem. 253, 1938-1943

Shank, R. P. \& Aprison, J. (1981) Life Sci. 28, 837-842 
Shank, R. P., Campbell, G. L., Freyteg, S. O. \& Utter, M. F. (1981) Abstr. Soc. Neurosci. 7, 936

Swain, J. L., Hines, J. J., Sabina, R. L., Harbury, O. L. \& Holmes, E. W. (1984) J. Clin. Invest. 74, 1422-1427

Van den Berg, C. J., Reijnierse, G. L. A., Blockius, G. G. D., Kroon, M. C., Ronda, G., Clarke, D. D. \& Garfinkel, D. (1976) in Metabolic Compartmentation and Neurotransmission: Relation to Brain Structure and Function (Berl, S., Clarke, D. D. \& Schneider, D., eds.), pp. 515-544, Plenum Press, New York

Yu, A. C., Schousboe, A. \& Hertz, L. (1982) J. Neurochem. 39, 954-960
Yu, A. C., Schousboe, A. \& Hertz, L. (1984) J. Neurochem. 42, 594-597

Yudkoff, M., Nissim, I., Kim, S., Pleasure, D., Hummeler, K. \& Segal, S. (1983a) Biochem. Biophys. Res. Commun. 115, 174-179

Yudkoff, M., Nissim, I., Pleasure, D., Kim, S., Hummeler, K. \& Segal, S. (1983b) in Glutamine, Glutamate and GABA in the Central Nervous System (Hertz, L., Kvamme, E., McGeer, E. G. \& Schousboe, A., eds.), pp. 389-398, Alan Liss, New York

Yudkoff, M., Nissim, I., Kim, S. U., Pleasure, D. \& Segal, S. (1984) J. Neurochem. 42, 283-286

Received 22 May 1985/2 October 1985; accepted 22 October 1985 